\title{
Adenotonsillectomy in Children with Recurrent Acute Tonsillitis: Review and Implications for Practice Adenotonsillectomy in Recurrent Acute Tonsillitis
}

\author{
Lorenzo Pignataro ${ }^{1}$, Tullio Ibba ${ }^{1}$, Paola Marchisio ${ }^{2}$ and Sara Torretta ${ }^{1 *}$ \\ 1Department of Clinical Sciences and Community Health, University of Milan, Otolaryngology Unit, Italy \\ 2Paediatric Highly Intensive Care Unit, Department of Patophysiology and Transplantation, Università degli Studi Milano, Italy
}

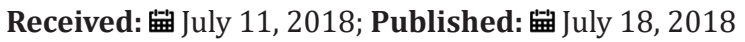

*Corresponding author: Sara Torretta, Department of Clinical Sciences and Community Health, University of Milan, Otolaryngology Unit, Italy.

\begin{abstract}
This paper aims at defining the therapeutic role of (adeno)tonsillectomy in children affected by recurrent acute tonsillitis (RAT), and at drawing some practical implications based on the current evidence. A literature search was performed to find pertinent study accessible by means of a MEDLINE search (accessed via PubMed). 15 papers were selected for literature analysis. The evidence suggests that although significant, the effect of tonsillectomy in children with moderate to severe RAT is modest and limited to 12 months post-operatively. In the case of patients with mild symptoms, it seems that the benefits are not sufficient to balance the disadvantages of the procedure. This can be explained by the fact that the procedure is intrinsically characterised by pharyngeal pain and that the surgical removal of a palatine tonsil does not exclude the subsequent onset of successive episodes of pharyngitis. An analysis of the literature indicates that the efficacy of (adeno)tonsillectomy in treating pediatric RAT is generally limited and relatively transient.
\end{abstract}

Keywords: Tonsillectomy; Children; Tonsillitis; Pharynx; Tonsils

\section{Introduction}

Acute pediatric pharyngotonsillary inflammation is very frequently encountered in clinical practice, and its symptoms often limit children's everyday activities. Furthermore, a number of children have recurrent or persistent symptoms characterised by a succession of acute infections associated with fever, pharyngeal pain, general malaise and, respiratory sleep disorders, and the limitations on their everyday activities cause them to miss school and prevent their parents from going to work. In such cases, (adeno)tonsillectomy can be considered, although it is necessary to consider the possible risks of surgery, including those related to the use of general anesthesia [1-3].

Although probably not the only cause, the palatine tonsils certainly play a major role in the genesis of episodes of recurrent acute pharyngeal inflammation, which means that, even if it cannot eliminate the risk, tonsillectomy could theoretically prevent further episodes of pharyngeal pain and/or reduce the severity of subsequent infections, thus improving the patient's quality of life [4]. However, it is still not clear whether an accompanying adenoidectomy can lead to a further clinical benefit in terms of the number and/or severity of infections [4]. This paper will provide an overview on pathogenesis and surgical treatment of recurrent acute tonsillitis (RAT) in children (Section 1) and it will review the therapeutic role of (adeno)tonsillectomy such patients to draw practical recommendations for clinical practice (Section 2).

\section{Section 1: Pathogenesis and Surgical Treatment of Pediatric Rat}

\section{Defining acute tonsillitis}

Pharyngeal pain may be due to infection of the pharynx and/or tonsils but, as there are no specific diagnostic criteria, it is difficult (if not impossible) to distinguish pharyngitis and tonsillitis in clinical practice and the literature often refers generically to "sore throat" [4]. Since the publication of the paper by Paradise et al. in the New England Journal of Medicine [5], many authors have differentiated tonsillar infections into severe, moderate or mild, but without specifying whether they are bacterial or viral, and so neither their site nor their etiology is defined. Nowadays, most authors define episodes of acute purulent tonsillitis as those that are medically documented as being characterised by the presence of pyrexia $\left(>38.3{ }^{\circ} \mathrm{C}\right)$, tonsillary exudate, and jugodigastric adenopathy, and requiring antibiotic treatment $[5,6]$.

Furthermore, the nosological terms "recurrent acute tonsillitis" (RAT) and "chronic tonsillitis" (CT) are usually used as synonyms, thus making it difficult to compare different trials. Burton [4] has 
recently defined RAT as the presence of at least two acute episodes in the preceding 12 months, and CT as the presence of persistent symptoms lasting more than three months; however, most authors define severe RAT as five episodes of acute tonsillitis a year, the presence of symptoms for at least a year, disabling episodes and limitations on everyday activities [7], whereas others continue to use Paradise's definition of at least five episodes a year in the two preceding years, or at least three a year in the three preceding years $[5,6]$. It should also be pointed out that, unlike in the case of acute rhinosinusitis, the term "CT" or "CT with recurrent acute exacerbations", which suggest the presence of chronic structural changes in tonsillar tissue with periodic acute episodes [8], should be avoided because of the absence of real chronic tonsillar inflammation associated with symptoms lasting for more than four weeks and permanent structural alterations [3].

\section{Etiopathogenesis of Recurrent Acute Tonsillitis}

Most episodes of acute tonsillitis are caused by viral infections (i.e. adenovirus, Epstein- Barr virus, bocaviruses, influenza and para-influenza viruses, rhinovirus, enteroviruses including coxsackievirus, coronavirus, respiratory syncytial virus, metapneumovirus and HIV) or bacterial infections (group A betahemolytic Streptococcus Pyogenes mainly transmitted by means of Flügge droplets from infected subjects or, more rarely, healthy carriers) [1]. Other bacterial species that have been less frequently encountered include group C and G streptococci, Haemophilus influenzae, Nocardia, Coriobacteriia, Neisseria gonorrhoeae, and members of the Fusobacteria and Borrelia families responsible for Vincent's angina, which is characterised by the onset of a unilateral ulcerous and necrotising form of tonsillitis [1]. Finally, some recent studies of children with RAT have highlighted the role played by bacterial biofilms: i.e. metabolically quiescent polymicrobial bacterial colonies inside a polysaccharide matrix that makes them extremely resistant to the action of the immune system and the administration of antibiotics [8-10].

\section{Tonsillar Surgery}

Tonsillar surgery has always been one of the most frequent pediatric procedures and is generally performed from the age of three years [4]. It is estimated that about 530,000 pediatric procedures were performed in the United States in 2006 [11], but an analysis of the published data shows that:

a) The total number of patients undergoing tonsillar surgery has decreased because of declining support for the focal infection theory, according to which the tonsils were the starting point of the spread of pathogens responsible for the development of remote and systemic processes such as rheumatic fever, endocarditis, myocarditis, pericarditis, glomerulonephritis, pancreatitis, chorea, arthritis, and even appendicitis and peptic ulcers [12].

b) The number of children undergoing traditional tonsillectomy in Europe has also decreased because of the greater use of alternative surgical techniques, including volume reduction [3,12]; a recent review by Stelter (2014) has highlighted the fact that 8,400 of the 68,800 patients undergoing tonsillar surgery every year undergo partial tonsillectomy [3]. c) Regardless of the technique used, most authors agree that the ability of tonsillectomy to reduce the number of episodes of RAT is limited to the first 12 post-operative months [3-6,1316].

\section{Extra-capsular tonsillectomy (ET)}

This refers to the complete removal of tonsillar tissue, which may be done using 'hot' electro-surgical instruments (mono- or bipolar electro cauters, lasers or radiofrequency instruments) for both dissection and hemostasis, or 'cold' dissection with a scalpel followed by electro-surgical hemostasis [17-21]. ET generally involves identifying the larger calibre afferent vessels during dissection and closing them outside the capsule by means of sutures or electro-surgical methods. This means that, regardless of the technique used, the peri-tonsillar pharyngeal musculature undergoes a substantial trauma that may expose the adjacent nervous and vascular structures to direct contact with saliva, thus leading to a bacterial super-infection that favours the development of some of the main morbidities associated with the procedure such as post-operative pain and bleeding (4.5\% of cases) [12]. Furthermore, the findings of some meta-analyses suggest that 'cold' techniques are associated with an increased risk of intraand early post-operative bleeding (i.e. within 24 hours according to the classification of Sarny et al.) [22], whereas 'hot' techniques are more subject to the risk of delayed post-operative bleeding (i.e. after $>24$ hours) [22] and severe post-operative pain [23,24].

\section{Tonsillotomy (TT)}

This procedure, which can be performed using many kinds of instruments (a CO2 laser, ultrasound scalpel, hot knife, bipolar scissors, bipolar radiofrequency coblator, microdebrider, or monopolar argon laser) [25-29], reduces the volume of tonsillar tissue medially up to the palatine arches, thus allowing the removal of the excess tissue extending into the oropharyngeal cavity while preserving the residual and immunologically active lateral tissue. It has been reported that, in comparison with ET, this procedure reduces post-operative pain and the risk of post-operative bleeding $[30,31]$ insofar as the extra-capsular vascular and nervous afferents are not exposed.

\section{Intra-capsular tonsillectomy (IT)}

The methods described above can also be used for an intracapsular tonsillectomy (the sub-total [90\%] removal of the tonsillar parenchyma) in which the piecemeal dissection medially reaches the tonsillar capsule without going beyond it but leaves it in a tonsillar cavity covered by intact muscle tissue [32-35]. Like TT (and for the same reason), this procedure generally leads to a lower risk of post-operative bleeding and pain than ET [33], but there are no specific indications for pediatric IT because ET is preferable in patients with RAT, and TT is preferable in those with obstructive hyperplasia.

\section{Section 2: Impact of Tonsillectomy on Pediatric Rat Methods}

Pertinent studies published until December 2017 were selected on January 2018 by means of a MEDLINE search (accessed via PubMed) using the following terms: "tonsillectomy and children 
and recurrent acute tonsillitis". We only considered fully accessible English language papers published in peer-reviewed journals and dealing with surgical management of TAR in children. Randomizedcontrolled studies, metanalysis and systematic reviews were selected. The reference lists were subsequently reviewed to ensure that all of the selected papers were truly relevant and identify any possibly overlooked and pertinent papers. Analysis of the literature was performed in order to separately evaluate the main efficacy outcomes (i.e. number and severity of episodes; number of days of pharyngeal pain; number of lost school days; tonsillectomy vs. adenotonsillectomy; long-term efficacy of surgery; surgery-related morbidity; comparison of instrumentation; impact of tonsillotomy and comparable reducing techniques on pediatric RAT); when there was a sufficient number of published studies, the results will be analysed using the GRADE Working Group's system of defining the overall quality of the evidence provided by the meta-analyses (Table 1) [36,37]. The quality of the evidence indicates the degree of certainty with which the correctness of an estimated effect can be accepted, and the parameter can be used to interpret the results [36,37].

Table 1: GRADE Working Group definitions of the overall quality of evidence [37,38].

\begin{tabular}{|c|c|}
\hline Level of evidence & Explanation \\
\hline High & $\begin{array}{l}\text { Further studies would probably not lead to any } \\
\text { substantial change in the estimate of effect. }\end{array}$ \\
\hline Moderate & $\begin{array}{l}\text { Further studies would probably have a significant } \\
\text { impact on the certainty of the estimate of the } \\
\text { effect and may change the estimate itself. }\end{array}$ \\
\hline Low & $\begin{array}{l}\text { Further studies would very probably have a } \\
\text { significant impact on the certainty of the estimate } \\
\text { of the effect snf would probably change the } \\
\text { estimate itself. }\end{array}$ \\
\hline Very low & $\begin{array}{l}\text { There is a high degree of uncertainty concerning } \\
\text { the estimate of the effect. }\end{array}$ \\
\hline
\end{tabular}

\section{Results}

15 out of 96 initially selected papers were considered for literature analysis. They included six randomized controlled trials. Evaluating effectiveness of surgical treatment in children with RAT it needs to be remembered that there is generally a discrepancy between the degree of subjective satisfaction expressed by the patients' parents and the objective clinical benefit of surgery as measured by means of standard parameters such as the number of episodes or the number of days of pharyngeal pain and their severity. It has recently been pointed out by some authors that, in addition to these classic criteria, it is also necessary to consider additional parameters that reflect the quality of life of both the patients and their families [38], such as psycho-social and educational factors, and general (fever, asthenia, nausea, etc.) and local symptoms (a sensation of pharyngeal burning, difficulties in swallowing, halitosis, cough, speaking difficulties, etc.). An analysis of the literature shows that the efficacy of tonsillectomy is limited to the 12 months following surgery and is mainly judged based on the reduction in the number of episodes and the severity of the symptoms [3-6,13-14]. In the case of patients with mild symptoms (unlike those experiencing moderately severe or severe episodes), it seems that the benefits are not sufficient to balance the disadvantages of the procedure, such as its direct and indirect costs, and the morbidity and complications arising from it $[2,4,5,6,12,24]$.

The following paragraphs discuss in detail the main efficacy outcomes.

Table 2: Summary of evidence and practical advice relating to tonsillectomy in pediatric patients with recurrent acute tonsillitis (RAT).

\begin{tabular}{|c|c|c|c|}
\hline \multicolumn{2}{|r|}{ Evidence } & \multicolumn{2}{|r|}{ Practical advice } \\
\hline 1 & $\begin{array}{l}\text { There is no cut-off age, but most } \\
\text { of procedures are performed in } \\
\text { children aged }>3 \text { years. }\end{array}$ & $\mathrm{A}$ & $\begin{array}{c}\text { Except for cases, } \\
\text { tonsillectomy can be } \\
\text { considered in children aged } \\
>3 \text { years. }\end{array}$ \\
\hline 2 & $\begin{array}{l}\text { There is no cut-off number of } \\
\text { episodes of pharyngeal pain, but } \\
\text { most authors refer to at least } \\
\text { six episodes in the } 12 \text { preceding } \\
\text { months. }\end{array}$ & A & $\begin{array}{c}\text { Tonsillectomy should } \\
\text { not be considered if the } \\
\text { number of episodes in the } \\
\text { preceding } 12 \text { months is }<5 \text {. }\end{array}$ \\
\hline & & & $\begin{array}{l}\text { In the presence of five } \\
\text { episodes, tonsillectomy can } \\
\text { be considered if at least } \\
\text { one further episode. }\end{array}$ \\
\hline & & & $\begin{array}{l}\text { Tonsillectomy should be } \\
\text { considered if the number of } \\
\text { episodes in the preceding } \\
12 \text { months is } \geq 6 \text {. }\end{array}$ \\
\hline 3 & $\begin{array}{l}\text { Tonsillectomy is moderately } \\
\text { beneficial in patients with severe } \\
\text { symptoms. }\end{array}$ & A & $\begin{array}{l}\text { Tonsillectomy can be } \\
\text { considered in the presence } \\
\text { of severe symptoms*. }\end{array}$ \\
\hline & & & $\begin{array}{l}\text { Tonsillectomy should be } \\
\text { considered in the presence } \\
\text { of recurrent episodes of } \\
\text { acute purulent tonsillitis**. }\end{array}$ \\
\hline & & & $\begin{array}{c}\text { Inform parents that } \\
\text { tonsillectomy does not } \\
\text { eliminate the risk of } \\
\text { subsequent pharyngeal } \\
\text { pain. }\end{array}$ \\
\hline 4 & $\begin{array}{l}\text { Tonsillectomy does not have any } \\
\text { significant benefit in patients } \\
\text { with mild symptoms. }\end{array}$ & A & $\begin{array}{l}\text { Tonsillectomy should not } \\
\text { be performed in patients } \\
\text { with mild symptoms. }\end{array}$ \\
\hline 5 & $\begin{array}{l}\text { The clinical benefit of } \\
\text { tonsillectomy not last for more } \\
\text { than } 12 \text { months after surgery. }\end{array}$ & A & $\begin{array}{l}\text { Inform parents of the } \\
\text { possibility of new } \\
\text { disturbances in the long } \\
\text { term. }\end{array}$ \\
\hline 6 & $\begin{array}{l}\text { Pain and the risk of post- } \\
\text { operative bleeding is less if 'cold' } \\
\text { surgical techniques are used. }\end{array}$ & A & $\begin{array}{l}\text { Prefer the use of 'cold' } \\
\text { surgical techniques. }\end{array}$ \\
\hline 7 & $\begin{array}{c}\text { Regardless of the technique } \\
\text { used, tonsillectomy can lead to } \\
\text { potentially serious complications. }\end{array}$ & A & $\begin{array}{l}\text { Inform parents of the } \\
\text { possible risks and teach } \\
\text { them what they can do to } \\
\text { minimise their onset and } \\
\text { how to deal with them. }\end{array}$ \\
\hline 8 & $\begin{array}{l}\text { RAT is not a contraindication } \\
\text { to tonsillotomy, but the risk } \\
\text { of requiring a subsequent } \\
\text { tonsillectomy to treat RAT is } \\
\text { considerable. }\end{array}$ & A & $\begin{array}{l}\text { Tonsillotomy should not } \\
\text { be considered in patients } \\
\text { with RAT. }\end{array}$ \\
\hline
\end{tabular}


9 There is no evidence that simultaneous adenoidectomy is clinically beneficial.
Adenoidectomy should not be considered unless there is a concomitant specific indication for it.

*Characterised by $\geq 5$ episodes in the preceding 12 months, and debilitating symptoms limiting everyday activities for at least one year.

**Characterised by clinically documented tonsillar exudate, hyperpyrexia $\left(>38.3{ }^{\circ} \mathrm{C}\right)$ and jugo-digastric lymphadenopathy and requiring antibiotic therapy.

\section{Number and Severity of Episodes}

Given the extreme variability of the studies, it is not possible to draw any definite conclusions nor establish any precise threshold values concerning patient selection criteria. However, most authors agree that surgery should be avoided in the case of patients who have experienced fewer than three documented episodes of tonsillitis during their lives $[2,12]$. Furthermore, given the high rate of spontaneous resolution, Windfuhr believes it is advisable to observe the patient for a period of three months to determine the real need for surgical treatment [12]. Although characterised by considerable heterogeneity (especially in relation to diagnostic criteria), recent meta-analyses $[4,12,24]$ indicate that the children undergoing surgery experience an average of $0.6 \%$ fewer episodes of pharyngeal pain of any severity during the 12 months after surgery, including the episode attributable to surgery (adenotonsillectomy or tonsillectomy vs no surgery (95\% confidence interval [CI] 0.11.0) than controls (five studies, 795 patients; GRADE: moderate) [4]. The patients undergoing (adeno)tonsillectomy experience 3.0 episodes (including the predictable episode of pharyngeal pain immediately after the operation) against the 3,6 episodes experienced by the children in the non-surgical group [4,12,24]. The difference is further reduced if the groups are stratified based on the severity of the episodes $[4,12,24]$ :

a) the only available study of patients experiencing moderate or severe episodes [5] documented 1.1 episodes in the surgical group (including the predictable episode immediately after the operation) vs 1.2 episodes in the non-surgical group (difference: 0.1, 95\% CI <0.4-0.6) (one study, 73 patients; GRADE: low) [4].

b) among the patients experiencing milder episodes, the benefit of surgery is annulled (1.2 vs 0.4 moderate or severe episodes, including the predictable episode immediately after the operation): difference: $0.8,95 \%$ CI $0.7-0.9$; three studies, 491 patients; GRADE: moderate) [4].

In conclusion, although significant, the modest effect of tonsillectomy on RAT can be explained by the fact that the procedure is intrinsically characterised by pharyngeal pain and that the surgical removal of a palatine tonsil does not exclude the subsequent onset of successive episodes of pharyngitis.

\section{Number of days of pharyngeal pain}

Surgery reduces the number of days of pharyngeal pain during the following 12 months by an average of 5.1 days (95\% CI 2.2-8.1) in comparison with no surgery (average 23.2 days, range 18.9-49.1)

(five studies, 776 patients; GRADE: moderate), including those in the immediate post-operative period [4].

\section{Number of lost school days}

Children undergoing surgery miss an average of 2.3 fewer school days (95\% CI 1.2-3.4) during the following 12 months because of pharyngeal pain (excluding the days immediately after surgery) than the average of six days lost by controls (four studies, 412 patients, GRADE: moderate) [4].

\section{Tonsillectomy vs adenotonsillectomy}

The only randomised clinical trial analysing this outcome [6] did not find any difference between the two approaches in terms of the number of episodes or the duration of pharyngeal pain after the operation. However, the limitations of the primary outcome and power of this study means that its conclusions may have been influenced by an underestimate due to the insufficient size of the sample [4]. Consequently, given the paucity of the number of studies, it is still not possible to say whether the addition of adenoidectomy reduces the frequency and severity of post-operative episodes of pharyngeal pain.

\section{Long-term efficacy of surgery}

Most of the available studies have a high percentage of patients (about 20\%) who were lost to follow-up, especially during the second and third years [3-6,13-16]. Only Stafford et al. (1986) [13] report the number of patients considered cured between 18 and 24 months after treatment: 18/20 (90\%) in the surgical group and $14 / 20(70 \%)$ in the non-surgical group (risk ratio 0.86, 95\% CI $0.57-1.29$ ) [4]. It is therefore not possible to say with any certainty whether surgical treatment has a significant impact on the history of RAT beyond 12 months.

\section{Surgery-related morbidity}

None of the studies included in the meta-analysis of [4] specifies which surgery-related morbidities were evaluated other than post-operative pain, for which the studies of [5,6] document an average of 4.9-6.3 days (range 0-21). The estimated overall rate of complications is $6.0-7.9 \%$ ) [5,6,39], which included early and late bleeding (respectively 1.5-4.8\% and 4.3-6.0\%), sometimes requiring surgical revision (including the ligation of neck vessels) or blood transfusions [4,6,12,24], nausea and vomiting (3.4\%) [14], the need for hospitalisation because of bleeding or severe post-operative pain $(2.1-4.3 \%)[4,6,12,24,40]$, anesthesia-related trismus, and the possible development of malignant hyperthermia $(0.5 \%)$ [6]. Other complications include iatrogenic lesions of the temporo-mandibular joint and the lips, tongue, teeth and uvula; tonsillar residues requiring surgical revision; dysphonia, rhinolalia and velo-palatal insufficiency; lesions of the hypoglossal, glossopharyngeal or vagus nerve, with consequent permanent or transient dysphagia and dysgeusia; purulent cervical infection; thrombosis of the internal jugular vein; cervico-facial emphysema; mediastinitis; and Griesel's syndrome [12] (GRADE: low) [4]. None of the studies included in the meta-analyses reported deaths among the surgical complications [4,24], but there have been some sporadic reports [41-43]. 


\section{Comparison of instrumentation}

The main outcome in this regard is the comparison of 'cold' and 'hot' surgery (surgical diathermy and coblation used for dissection and hemostasis) in terms of bleeding. The main systematic reviews $[4,24]$ indicate that electro-surgery leads to a greater risk of delayed post-operative bleeding (including cases requiring surgical revision) than cold dissection using a blade and surgical ligation (9 studies, 780 patients; GRADE: very low) [4]. The latter approach is associated with a lower overall risk of post-operative bleeding (1.7-2\%), but a greater risk of intra-operative bleeding [24]. Cold surgical dissection with selective bipolar hemostasis is characterised by the lowest risk post-operative bleeding requiring surgical revision (0-0.7\%) [24].

\section{Impact of tonsillotomy and comparable reducing techniques on pediatric RAT}

Once again, the published clinical experiences are highly heterogeneous in terms of surgical techniques and successful outcomes. However, a recent systematic review of 86 studies involving a total of 20,950 patients has found that the frequency of TT and IT is similar (respectively $43 \%$ and $41 \%$ ), whereas ablative procedures (tonsillar ablation using radiofrequency, laser or coblator) account for $16 \%$ [44]. A microdebrider is the most frequently used instrument, but it is still not possible to draw any definite conclusions concerning its advantages over others. About the indications for surgery, TT is generally used to reduce the volume of tonsils obstructing the upper airways in patients with RAT, which most authors do not consider a contraindication to TT [45-47]. Given the lack of specific information in more than half of the studies, it is not possible to make a comparative metaanalysis of the different approaches in terms of the duration of the procedure, post-operative pharyngeal pain or tonsillar regrowth. The only thing that can be said is that partial or sub-total removal takes less time than traditional tonsillectomy, and causes less intra-operative bleeding, and post-operative pain and dysphagia [31]. TT is characterised by a $0.26 \%$ (range $0-2.5 \%$ ) risk of postoperative bleeding requiring surgical revision, and a level of postoperative pain of 2-3 on a 0 -10 visual analogue scale (VAS) whereas a traditional tonsillectomy is associated with an average VAS score of $5[3,12,20,29,48,49]$. On the other hand, the median risk of postTT tonsillar regrowth and RAT are respectively 3.0\% (0-26.9\%) and $3.9 \%(0-16.3)$, and tonsillectomy is necessary to correct the regrowth or RAT in a median of $1.5 \%$ of cases $(0-11.9 \%)$ [12].

\section{Discussion and Practical Implications}

There is still no published consensus concerning the age-related number of previous episodes of acute purulent tonsillitis associated with pyrexia (>38.3 $\left.{ }^{\circ} \mathrm{C}\right)$, tonsillar exudate and jugodigastric lymphadenopathy, and requiring antibiotic treatment, that identifies candidates for surgery (Table 2). Furthermore, the high rate of spontaneous resolution suggests the appropriateness of a six-month period of observation to verify the real need for surgical treatment (Table 2).

An analysis of the literature indicates that the efficacy of (adeno)tonsillectomy in treating pediatric RAT is generally limited and relatively transient $[4,12,24]$. a) Children with moderate or severe episodes (according to the criteria of Paradise et al.) [5] who undergo surgery generally experience a significant but predictable period of pharyngeal pain immediately after surgery and a further two episodes in the subsequent 12 months (1 predictable +2 unpredictable episodes $=3$ episodes in total) against an average of 3.6 unpredictable episodes in conservatively treated patients; however, depending on the case series, this average difference of 0.6 episodes may vary from 0.1 to 1.0 episodes, and so there may be no real difference between the two groups.

b) In children with milder episodes, the reduction in the risk of developing subsequent moderate or severe episodes because of surgery is even less ( 1 predictable +0.2 unpredictable episodes $=1.2$ episodes in total vs 0.4 unpredictable episodes in conservatively treated children).

c) Children undergoing surgery experience an average of 1823 days of pharyngeal pain in the subsequent 12 months, but these include the 5-7 days following the operation.

d) The clinical benefit of surgical treatment is only apparent during the first 12 post-operative months.

Although tonsillectomy seems to have a positive impact on the quality of life, analysis of the literature reveals that there is an urgent need for controlled studies using standardised and reproducible parameters. Based on the currently available data, it is advisable in clinical practice to inform the parents of children with RAT who are candidates for tonsillectomy that, although significant, the clinical benefit in terms of the reduction in the number of episodes of pharyngeal pain may be limited in the presence of severe symptoms and non-existent in the case of mild symptoms, for which non-surgical treatment should be considered (Table 2). Cold tonsillectomy seems to be the technique that is least burdened by pain and the risk of post-operative bleeding, but also seems to be characterised by a slight increase in the risk of intra-operative bleeding. On the contrary, the use of electro-surgery is associated with a lower risk of early bleeding, but an increased risk of delayed post-operative bleeding (and estimated overall bleeding), and so its use in clinical practice needs to be carefully weighed against its potential disadvantages and, if possible, it should be avoided (Table 2).

Although a lack of data and the absence of appropriate followup in a considerable number of case series makes it impossible to reach a sufficient level of evidence to indicate the superiority of TT, the available data suggest that it and comparable procedures are better tolerated than traditional tonsillectomy in terms of the duration of surgery, intra-operative bleeding, the resumption of oral feeding, pain, and post-operative complications. Analysis of the literature also shows that it is generally less frequently performed than tonsillectomy, and none of the guidelines include it among the therapeutic strategies for patients with RAT [12] except for the recent German guidelines, which mention it as a possible alternative to traditional tonsillectomy in patients who have experienced at least six episodes in the preceding 12 months or 3-5 episodes after a 6-month observation period during which it is mandatory to reach a total of at least six episodes, regardless 
of the degree of tonsillar hypertrophy (which must in any case be $>1$ according to Brodsky's classification). This position is supported by the fact that the available evidence suggests that TT resolves upper airway obstruction and improves the natural history of patients with RAT, and the fact that there are still no studies proving the superiority of tonsillectomy over volume reduction in such patients. However, although not generally very high, the risks of tonsillar regrowth, the onset of RAT requiring surgical revision, and subsequent tonsillectomy have respectively reached $27 \%, 16 \%$ and $12 \%$ in some case series [12], and so the decision to perform TT in a patient with a history of RAT should be made very cautiously (Table 2). Finally, there is currently no evidence to suggest that simultaneous adenoidectomy and tonsillar surgery is clinically beneficial in patients with RAT, and so adenotonsillectomy should only be performed in the presence of specific conditions (Table 2).

\section{References}

1. Windfuhr JP, Toepfner N, Steffen G, Waldfahrer F, Berner R (2016) Clinical practice guideline: tonsillitis I. Diagnostics and nonsurgical management. Eur Arch Otorhinolaryngol 273(4): 973-987.

2. Windfuhr JP (2016) Indications for tonsillectomy stratified by the level of evidence. GMS Curr Op Otorhinolaryngol Head Neck Surg 15: Doc09.

3. Stelter K (2014) Tonsillitis and sore throat in children. GMS Curr Op Otorhinolaryngol Head Neck Surg 13: Doc07.

4. Burton MJ, Glasziou PP, Chong LY, Venekamp RP (2014) Tonsillectomy or adenotonsillectomy versus non-surgical treatment for chronic/ recurrent acute tonsillitis (Review). Cochrane Database Syst Rev 11: CD001802.

5. Paradise JL, Bluestone CD, Bachman RZ (1984) Efficacy of tonsillectomy for recurrent throat infection in severely affected children. Results of parallel randomized and nonrandomized clinical trials. N Engl J Med 310(11): 674-683.

6. Paradise JL, Bluestone CD, Colborn DK, Bernard BS, Rockette HE, et al. (2002) Tonsillectomy and adenotonsillectomy for recurrent throat infection in moderately affected children. Pediatrics 110: 7-15.

7. Pinder DK, Wilson H, Hilton MP (2011) Dissection versus diathermy for tonsillectomy. Cochrane Database Syst Rev 16: CD002211.

8. Torretta S, Drago L, Marchisio P, Cappadona M, Rinaldi V, et al. (2013) Recurrences in chronic tonsillitis sustained by tonsillar biofilmproducing bacteria in children. Relationship with the grade of tonsillar hyperplasy. Int J Pediatr Otorhinolaryngol 77(2): 200-224.

9. Torretta S, Marchisio P, Drago L, Capaccio P, Baggi E, et al. (2015) The presence of biofilm-producing bacteria on tonsils is associated with increased exhaled nitric oxide levels: preliminary data in children who experience recurrent exacerbations of chronic tonsillitis. J Laryngol Otol 129(3): 267-272.

10. Nazzari E, Torretta S, Pignataro L, Marchisio P, Esposito S (2015) Role of biofilm in children with recurrent upper respiratory tract infections. Eur J Clin Microbiol Infect Dis 34(3): 421-429.

11. Patel HH, Straight CE, Lehman EB, Tanner M, Carr MM (2014) Indications for tonsillectomy: a 10 years retrospective review. Int J Ped Otorhinolaryngol 78(12): 2151-2155.

12. Windfuhr JP, Toepfner N, Steffen G, Waldfahrer F, Berner R (2016) Clinical practice guideline: tonsillitis II. Surgical management. Eur Arch Otorhinolaryngol 273(4): 989-1009.

13. Stafford N, von Haacke N, Sene A, Croft C (1986) The treatment of recurrent tonsillitis in adults. J Laryngol Otol 100(2): 175-177.

14. Van Staaij BK, Van den Akker EH, Rovers MM, Hordijk GJ, Hoes AW, et al. (2004) Effectiveness of adenotonsillectomy in children with mild symptoms of throat infections or adenotonsillar hypertrophy: open, randomised controlled trial. BMJ 329: 651.
15. Lock C, Wilson J, Steen N, Eccles M, Mason H, et al. (2010) North of England and Scotland Study of Tonsillectomy and Adeno-tonsillectomy in Children (NESSTAC): a pragmatic randomized controlled trial with a parallel non-randomised preference study. Health Technol Assess 14(13): 1-164.

16. Wilson JA, Steen IN, Lock CA, Eccles MP, Carrie S, et al. (2012) Tonsillectomy: a cost-effective option for childhood sore throat? Further analysis of a randomized controlled trial. Otolaryngol Head Neck Surg 146(1): 122-128.

17. Kristensen S, Tveterås K (1984) Post-tonsillectomy haemorrhage. A retrospective study of 1150 operations. Clin Otolaryngol Allied Sci 9(6): 347-350.

18. Andrea M (1993) Microsurgical bipolar cautery tonsillectomy. Laryngoscope 103(10): 1177-1178.

19. Watson MG, Dawes PJ, Samuel PR (1993) A study of haemostasis following tonsillectomy comparing ligatures with diathermy. J Laryngol Otol 107(8): 711-715.

20. Lassaletta L, Martín G, Villafruela MA, Bolaños C, Alvarez-Vicent JJ (1997) Pediatric tonsillectomy: post-operative morbidity comparing microsurgical bipolar dissection versus cold sharp dissection. Int J Pediatr Otorhinolaryngol 41(3): 307-311.

21. Ewah B (2006) An evaluation of pain, postoperative nausea and vomiting following the introduction of guidelines for tonsillectomy. Paediatr Anaesth 16(10): 1100-1101.

22. Sarny S, Ossimitz G, Habermann W, Stammberger H (2012) The Austrian tonsil study 2010-part 1: statistical overview. Laryngorhinootologie 91(1): 16-21.

23. Georgalas CC, Tolley NS, Narula A (2009) Tonsillitis. BMJ Clin Evid 26: 0503.

24. Georgalas CC, Tolley NS, Narula A (2014) Tonsillitis. Clinical Evidence 7: 503-516.

25. Leinbach RF, Markwell SJ, Colliver JA, Lin SY (2003) Hot versus cold tonsillectomy: a systematic review of the literature. Otolaryngol Head Neck Surg 129(4): 360-364.

26. Unkel C, Lehnerdt G, Schmitz KJ, Jahnke K (2005) Laser-tonsillotomy for treatment of obstructive tonsillar hyperplasia in early childhood: a retrospective review. Int J Pediatr Otorhinolaryngol 69(12): 1615-1620.

27. Davies J, Coatesworth AP (2005) Double-blind randomized controlled study of coblation tonsillotomy versus coblation tonsillectomy on postoperative pain. Clin Otolaryngol 30(6): 572-573.

28. Lister MT, Cunningham MJ, Benjamin B, Williams M, Tirrell A, et al. (2006) Microdebrider tonsillotomy vs electrosurgical tonsillectomy: a randomized, double-blind, paired control study of postoperative pain. Arch Otolaryngol Head Neck Surg 132(6): 599-604.

29. Pfaar O, Spielhaupter M, Schirkowski A, Wrede H, Mosges R, et al. (2007) Treatment of hypertrophic palatine tonsils using bipolar radiofrequencyinduced thermotherapy (RFITT). Acta Otolaryngol 127(11): 1176-1181.

30. Scherer H (2003) Tonsillotomy versus tonsillectomy. Laryngorhinootologie 82(11): 754-755.

31. Cantarella G, Viglione S, Forti S, Minetti A, Pignataro L (2012) Comparing postoperative quality of life in children after microdebrider intracapsular tonsillotomy and tonsillectomy. Auris Nasus Larynx 39(4): 407-410.

32. Sorin A, Bent JP, April MM, Ward RF (2004) Complications of microdebrider-assisted powered intracapsular tonsillectomy and adenoidectomy. Laryngoscope 114(2): 297-300.

33. Sobol SE, Wetmore RF, Marsh RR, Stow J, Jacobs IN (2006) Postoperative recovery after microdebrider intracapsular or monopolar electrocautery tonsillectomy: a prospective, randomized, single-blinded study. Arch Otolaryngol Head Neck Surg 132(3): 270-274.

34. Vaughan AH, Derkay CS (2007) Microdebrider intracapsular tonsillectomy. ORL J Otorhinolaryngol Relat Spec 69: 358-363. 
35. Windfuhr JP, Werner JA (2013) Tonsillotomy: it's time to clarify the facts. Eur Arch Otorhinolaryngol 270(12): 2985-2996.

36. Andrews JC, Schunemann HJ, Oxman AD (2013) GRADE guidelines: 15. Going from evidence to recommendation determinants of a recommendation's direction and strength. J Clin Epidemiol 66(7): 726735.

37. Andrews J, Guyatt G, Oxman AD (203) GRADE guidelines: 14. Going from evidence to recommendations: the significance and presentation of recommendations. J Clin Epidemiol 66(7): 719-725.

38. Barraclough J (2014) The role of tonsillectomy for recurrent sore throats in children: a qualitative study. Int J Pediatr Otorhinolaryngol 78(11): 1974-1980.

39. Alho OP, Koivunen P, Penna T, Teppo H, Koskela M, et al. (1997) Tonsillectomy versus watchful waiting in recurrent streptococcal pharyngitis in adults: randomized controlled trial. BMJ 334: 939.

40. Koskenkorva T, Koivunen P, Koskela M, Niemela O, Kristo A, et al. (2013) Short term outcomes of tonsillectomy in adult patients with recurrent pharyngitis: a randomized controlled trial. CMAJ: Canadian Medical Association Journal 185(8): E331-E336.

41. Windfuhr JP, Schloendorff G, Baburi D, Kremer B (2008) Lethal outcome of post-tonsillectomy hemorrhage. Eur Arch Otorhinolaryngol 265(12): 1527-1534.

ISSN: 2574-1241

DOI: 10.26717/BJSTR.2018.07.001440

Evans Paul Kwame Ameade1. Biomed J Sci \& Tech Res

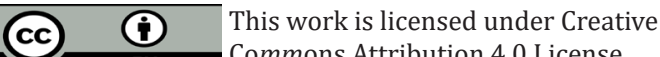

Submission Link: https://biomedres.us/submit-manuscript.php
42. Windfuhr JP, Schloendorff G, Baburi D, Kremer B (2008) Life-threatening post tonsillectomy hemorrhage. Laryngoscope 118(8): 1389-1394.

43. Windfuhr JP, Schloendorff G, Baburi D, Kremer B (2008) Serious posttonsillectomy hemorrhage with and without lethal outcome in children and adolescents. Int J Pediatr Otorhinolaryngol 72(7): 1029-1040.

44. Windfuhr JP, Savva K, Dahm J, Werner JA (2015) Tonsillotomy: facts and fiction. Eur Arch Otorhinolaryngol 272(14): 949-969.

45. Remacle M, Keghian J, Lawson G, Jamart J (2003) Carbon dioxide-laser assisted tonsil ablation for adults with chronic tonsillitis: a 6-months follow-up study. Eur Arch Otorhinolaryngol 260(8): 456-459.

46. Arya A, Donne A, Nigam A (2003) Double-blind randomized controlled study of coblation tonsillotomy versus coblation tonsillectomy on postoperative pain. Clin Otolaryngol 28(6): 503-506.

47. Andrews PJ, Latif A (2004) Outpatient laser tonsillar ablation under local anaesthetic. Eur Arch Otorhinolaryngol 261(10): 551-554.

48. Nelson LM (2000) Radiofrequency treatment for obstructive tonsillar hypertrophy. Arch Otolaryngol Head Neck Surg 126(6): 736-740.

49. Nelson LM (2003) Temperature-controlled radiofrequency tonsil reduction in children. Arch Otolaryngol Head Neck Surg 129(5): 533537.

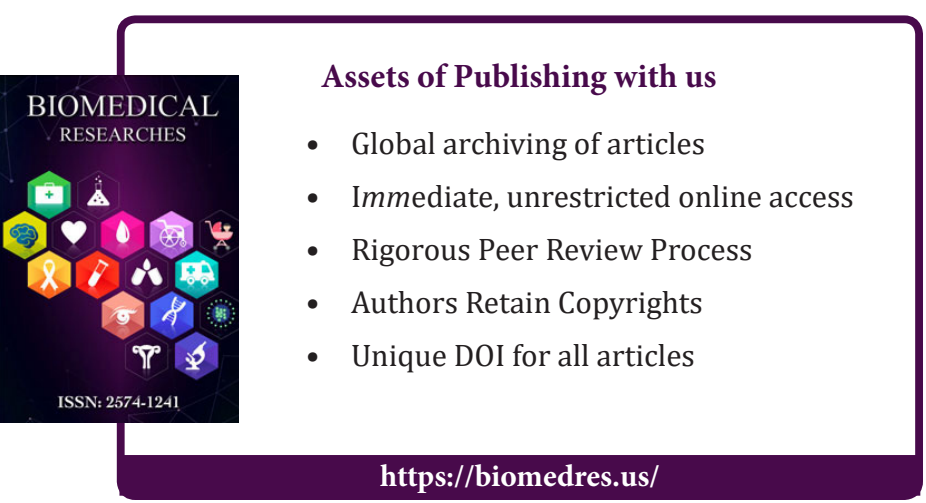

